\title{
Treatment with sera from Water Polo athletes activates AMPKa and ACC proteins In HepG2 hepatoma cell line
}

\author{
Rita Polito $^{1,2} \cdot$ Maria Ludovica Monaco $^{3} \cdot$ Marta Mallardo ${ }^{1,3} \cdot$ Ausilia Elce $^{4} \cdot$ Aurora Daniele $^{1,3}$ (1) $\cdot$ Ersilia Nigro $^{1,3}$
}

Received: 30 October 2020 / Accepted: 4 February 2021 / Published online: 4 June 2021

(c) The Author(s) 2021

\begin{abstract}
Purpose Physical activity and professional physical activity such as water polo (WP) sport, has numerous beneficial effects to fight metabolism-related disorders through several mechanisms, including the promotion of liver metabolic adaptations, and the modulation of cytokine production. The aim of this study was to investigate the effects of different types of physical activity on AMPK $\alpha$ and ACC, two proteins involved in liver metabolism; therefore, we treated the hepatoma cell line Hep G2 with sera from elite WP athletes and amateur (basket) players. As control, we used serum from both sedentary and obese subjects.

Methods Help G2 cells were treated with 5\% of human sera from the different subjects; after $24 \mathrm{~h}$ and $48 \mathrm{~h}, \mathrm{HepG} 2$ cell viability was verified through MTT assay and activation status of AMPK $\alpha$ and ACC through western blotting. Cytokine's serum levels were measured through ELISA assay.

Results After $72 \mathrm{~h}$, the treatment of HepG2 cells with sera from the different subjects produced no effect on cell viability. Furthermore, after $48 \mathrm{~h}$ of treatment, both AMPK $\alpha$ and ACC phosphorylation statistically increases in HepG 2 cells treated with sera from WP athletes. Furthermore, IL-4, IL-6 and IL-10 levels resulted statistically increased in WP athlete's sera than in sedentary subjects.

Conclusion The specific activation of AMPK $\alpha$ and ACC by WP sera confirms that professional sport activity carried out by WP athletes can be considered as a physiological activator of these two proteins also in HepG2 liver cells. In addition, the increase of anti-inflammatory cytokines in WP sera confirms the ample evidence for multiple anti-inflammatory activities carried out by WP discipline.
\end{abstract}

Keywords Hepatoma cells $\cdot$ Physical activity $\cdot$ Obesity $\cdot$ Cytokines $\cdot$ Water polo

\section{Introduction}

Rita Polito and Ersilia Nigro have contributed equally to this work.

Aurora Daniele

aurora.daniele@unicampania.it

1 Dipartimento di Scienze e Tecnologie Ambientali Biologiche Farmaceutiche, CEINGE-Biotecnologie Avanzate, Università Degli Studi Dellalla Campania "Luigi Vanvitelli”, via G. Salvatore 486, 80132 Napoli, Italy

2 Dipartimento di Sanità Pubblica, Università Degli Studi di Napoli "Federico II", Via S. Pansini 5, 80131 Napoli, Italy

3 Dipartimento di Scienze e Tecnologie Ambientali, Biologiche, Farmaceutiche, Università Della Campania "Luigi Vanvitelli", via A. Vivaldi 43, 81010 Caserta, Italy

4 Dipartimento di Scienze Umanistiche, Università Telematica Pegaso, Naples, Italy
Nutrition and physical activity affect general health status [1]. In addition, physical exercise is considered to be the most potent non-pharmacological intervention to manage hepatic alterations. Indeed, regular physical activity beneficially impacts on the risk of hepatic chronic diseases onset and progression. However, research regarding the effects of exercising on chronic liver diseases is relatively recent and not fully explored. Increasing clinical and experimental data focused on liver diseases finding that there is a cross-talk among skeletal muscle, adipose tissue and liver that regulates intrahepatic fat storage [2,3]. In this setting, physical activity allows an effective decrease of intrahepatic lipid component, and, despite that evidence is not conclusive, several studies suggest that a vigorous activity might be more effective than moderate activity in improving steatohepatitis 
[2-5]. On the other hand, evidence regarding the effects of exercise on the risk of hepatocellular carcinoma is scarce; some epidemiological studies indicate a lower risk in patients regularly and vigorously exercising. Among metabolic diseases, obesity is a chronic disease mainly due to excessive fat accumulation that may seriously impair health $[2,3]$. During the last 20 years, obesity has rapidly become a global pandemic health problem, often associated with insulin resistance, diabetes mellitus and dyslipidaemias. In addition, several data demonstrated that concomitant presence of obesity and insulin resistance might be associated with the development of liver diseases [4]. Indeed, visceral fat mass is a predictor not only of hyperinsulinaemia and insulin resistance but also of hepatic steatosis [5]. Furthermore, insulin is involved in the regulation of liver free fatty acids (FFA) metabolism and can inhibit hepatic mitochondrial beta-oxidation of FFA while, on the other hand, FFA accumulation in the liver may influence insulin clearance and insulin resistance initiating an unhealthy vicious circle [6]. For these reasons, a sedentary lifestyle is closely associated to an increased risk of mortality and morbidity for dysmetabolic diseases such as liver diseases and physical activity has an important role in its prevention [7-9]. Indeed, regular exercise promotes favourable muscle construction and metabolic adaptations [10]. However, it is important to distinguish between regular physical activity and athletic and professional physical activity. Water Polo (WP) is an aquatic team sport characterized by a combination of both aerobic and anaerobic efforts that requires intensive training and a high metabolic demand on the athletes [11]. Increased energy expenditure, reduced fat depots and promotion of beta-oxidation are at basis of professional sport, such as WP, beneficial effects [12]. Given the skeletal muscle cross-talking to the adipose tissue and the liver, professional physical activity has numerous beneficial effects not only on metabolic pathways but also on inflammatory processes, regulating cytokines response. In this contest, a key role is played by the pro-inflammatory cytokines, especially tumor necrosis factor-alpha (TNF- $\alpha$ ) and IL-6 [7, 8, 13]. In particular, physical exercise is also able to reverse the imbalance in pro- and anti-inflammatory cytokines, phenomenon at the basis of many inflammatory processes, and to contribute to an overall decline of systemic inflammation $[14,15]$. Several studies, dealing with the association between exercise and inflammation, affirm that physical activity has an antiinflammatory effect in various pathological and physiological states characterized by low-grade inflammation, such as ageing, metabolic disease, obesity, etc. [16-18]. The anti-inflammatory response induced by physical activity is mediated by the muscle endocrine functions; indeed, during contraction, muscle-derived cytokines, named myokines, are released to regulate both muscle metabolism [19]. Literature data report that circulating levels of anti-inflammatory cytokines rise and those of the pro-inflammatory adipokines such as tumor necrosis factor alpha (TNF $\alpha$ Interferon gamma INF $\gamma$ and interleukin (IL)-2 decrease as a result of the regular and moderate physical activity [16]. Indeed, the pattern of cytokines induced by physical activity is typically antiinflammatory, with a marked increase in serum levels of several cytokines, such as IL-10, IL-4, and IL-6 [20-22]. Furthermore, the release of IL6 after intense physical exercise as in athletes is reported to create an anti-inflammatory environment [13, 23, 24].

In this scenario, this study investigated the effects of sera from professional, amateur, inactive and obese subjects on hepatic cells. To this aim, we treated the hepatoma cell line, Hep G2, to find out if sera from different trained subjects could induce a different biological response. In particular, we aimed at clarifying if the treatment with the above-mentioned sera affects cell viability and/or the activation status of AMPK $\alpha$ and ACC, two proteins involved in different molecular pathways linked to metabolism [25, 26]. Considering that our data show that the treatment with Water Polo player's sera induces relevant effects on AMPK $\alpha$ and ACC, we analysed the serum cytokine levels (IL-2, IL-4, IL-6, IL-8, IL-10, TNF- $\alpha$, GM-CSF and IFN $\gamma$ in these professional athletes' respect to control subjects.

\section{Materials and methods}

\section{Participants}

22 unrelated professional international level men's Water Polo players were recruited from Circolo Nautico Posillipo, Napoli, Italy. At investigation time, the athletes performed 2 sessions of training/day with a competition taking place during the week end. Generally, the sessions of training consisted of technical-tactical drills, swimming, and strength training (60-120 min/session) as previously reported [27]. Three male basket players were recruited from an amateur team in Naples and three obese subjects were recruited as previously reported [28]. 20 age- and sex-male matched sedentary healthy volunteers were recruited from CEINGEBiotecnologie Avanzate staff. The study was conducted according to the guidelines of the Declaration of Helsinki and approved by the Ethics Committee of University of Campania “L. Vanvitelli" (Prot. n. 587/18). All participants signed informed consent. WP samples were collected after an overnight fast $(12 \mathrm{~h})$ before training session.

\section{Cell culture and treatments}

Cell lines derived from liver, Hep G2 (ATCC) were kindly provided from the Bank of Human and Animal Continuous Cell Lines CEINGE-Biotecnologie Avanzate. Cells were 
cultured in RPMI medium supplemented with $10 \%$ FBS, L-glutamine (1\%), penicillin/streptomycin (1\%).

Human sera were decomplemented at $95^{\circ} \mathrm{C}$ for $30 \mathrm{~min}$ before the treatments.

\section{Viability assay}

Cell viability was measured by the 3-(4,5-dimethylthiazol2-yl)-2,5-diphenyltetrazolium bromide (MTT) assay. Briefly, $4 \times 10^{6}$ Hep G2 cells were seeded in 96-well plates and incubated with:- $5 \%$ sera from-Water polo athletes,-basket amatorial players,- - obese subjects, and-healthy controls. After 24, 48, and $72 \mathrm{~h}$ of incubation, cells were stained with MTT solution (3-[4,5-dimethylthiazol-2-yl]-2,5-dipheniltetrazolium-bromide/PBS) as previously reported [29]. All data are presented as mean $\pm \mathrm{SE}$ of three independent experiments.

\section{Protein extraction and western blotting}

Hep G2 cells were incubated for 24 and $48 \mathrm{~h}$ with: $-5 \%$ sera from-Water polo players,- - basket players,- obese subjects, or-healthy controls. After incubation times, cells were lysed and homogenized in RIPA buffer $(20 \mathrm{mM}$ Tris- $\mathrm{HCl} \mathrm{pH} 7.5,150 \mathrm{mM} \mathrm{NaCl}, 10 \%$ glycerol, $1 \mathrm{mM}$ $\mathrm{Na}_{3} \mathrm{OV}_{4}, 1 \mathrm{mM} \mathrm{NaF}, 1 \%$ Triton X100, 0.1\% SDS, $1 \% \mathrm{Na}$ deoxycholate) containing $1 \mathrm{mM}$ PMSF and protease inhibitors. Proteins were quantified by the Bradford method. $25 \mu \mathrm{g}$ of proteins were dissolved in 1X Laemmli buffer and separated using 10\% SDS-PAGE gel and the electrophoresis was performed as previously described [30]. The membranes were incubated with p-ACC, ACC, p-AMPK $\alpha$, AMPK $\alpha$ (Cell-Signaling Technology, MA) and GAPDH primary antibody (Sigma-Aldrich, MO, USA) according to the manufacturer's instructions. Enhanced chemiluminescence (ECL) (Euroclone) was employed to detect the HRP secondary antibody signal. To conclude, protein bands were detected with ChemiDoc XRS (Bio-Rad) and quantified with Image J software (http://rsbweb.nih.gov.ij/). Each treatment was performed two times in triplicate.

\section{Cytokines quantification}

Sera from Water Polo athletes and sedentary healthy controls were screened for the concentration of IL-2, IL-4, IL-6, IL- 8 , IL-10, TNF- $\alpha$, GM-CSF and IFN- $\gamma$. Measurements were performed with the Bio-Plex human cytokine kit from BioRad (BioRad, Hercules, CA, USA), according to the manufacturer's protocol.

\section{Statistical analysis}

Data are means \pm SE. Two groups were compared with 2-tailed unpaired Student's $t$ test. Multiple comparisons were performed by ANOVA test. All statistical analyses were performed using the StatView software 5.0.1.0. Differences were considered statistically significant when $P<0.05$.

\section{Results}

\section{Anthropometric and biochemical features measurements}

The anthropometric and biochemical characteristics of Water Polo players have been previously reported [27]. The anthropometric and biochemical characteristics of basket players, obese patients and sedentary healthy control subjects are shown in Table 1. Compared to controls, WP have significant reduced levels of total cholesterol $(P<0.05)$ (Table 1). No significant differences were found in HDL, triglycerides, and glucose. Obese

Table 1 Biochemical features of Obese patients, water polo players, basket players and controls

\begin{tabular}{|c|c|c|c|c|c|c|c|}
\hline Parameters & Controls & Obese & WP players & BK Players & $\begin{array}{l}\text { Controls vs. } \\
\text { Obese } P \text { value }\end{array}$ & $\begin{array}{l}\text { Controls vs. Water } \\
\text { Polo players } P \text { value }\end{array}$ & $\begin{array}{l}\text { Controls } V s . \\
\text { Basket Players } P \\
\text { value }\end{array}$ \\
\hline Sex male/female & $20 / 0$ & $3 / 0$ & $22 / 0$ & $3 / 0$ & - & - & - \\
\hline Age (years) & $34 \pm 3$ & $31 \pm 6$ & $27 \pm 5$ & $31 \pm 1$ & 0.84 & 0.08 & 0.40 \\
\hline BMI $\left(\mathrm{kg} / \mathrm{m}^{2}\right)$ & $26 \pm 2$ & $46 \pm 4$ & $25 \pm 1$ & $23 \pm 0.9$ & 0.01 & 0.29 & 0.06 \\
\hline Waist circumference $(\mathrm{cm})$ & $<94 \pm 7$ & $>110 \pm 4$ & $<94 \pm 5$ & $<94 \pm 6$ & 2.33E-05 & 0.56 & 0.62 \\
\hline Total Cholesterol (mg/dl) & $198 \pm 34$ & $164 \pm 35$ & $174 \pm 25$ & $171 \pm 7$ & 0.06 & 0.04 & 0.64 \\
\hline HDL (mg/dl) & $53 \pm 0.4$ & $35 \pm 2$ & $57 \pm 12$ & $55 \pm 2$ & 0.01 & 0.34 & 0.48 \\
\hline $\mathrm{LDL}(\mathrm{mg} / \mathrm{dl})$ & $90 \pm 1$ & $100 \pm 34$ & $101 \pm 21$ & $98 \pm 7$ & 0.06 & 0.06 & 0.21 \\
\hline Triglycerides (mg/dl) & $55 \pm 5$ & $144 \pm 39$ & $89 \pm 39$ & $93 \pm 13$ & 0.02 & 0.09 & 0.12 \\
\hline Glycemia (mg/dl) & $92 \pm 6$ & $97 \pm 4$ & $84 \pm 8$ & $95 \pm 6$ & 0.12 & 0.06 & 0.40 \\
\hline Fibrinogen (mg/dl) & $337 \pm 24$ & $354 \pm 13$ & - & - & 0.27 & - & - \\
\hline
\end{tabular}


subjects compared to controls have significant higher weight, BMI, waist circumference, triglycerides and lower HDL levels $(P<0.05)$. No statistically differences were found in LDL, glucose and fibrinogen. No differences were found between controls and basket players.

\section{Effects of sera treatments on HepG2 Cell viability}

To investigate the effects on cell viability induced by sera from sedentary, active subjects and professional athletes, we treated Hep G2 cells for $24 \mathrm{~h}, 48 \mathrm{~h}$ and $72 \mathrm{~h}$ with 5\% sera from Water Polo athletes, amateur basket players, obese and healthy control subjects. Our results showed that cell viability was not affected by the treatment with sera from the different trained subjects, both after $24 \mathrm{~h}$, $48 \mathrm{~h}$ and $72 \mathrm{~h}$ of incubation (Fig. 1).

\section{AMPKa and ACC analysis by Western blot}

We investigated the activation status of AMPK $\alpha$ and ACC enzymes following cell treatment with sera from sedentary healthy controls, obeses, active subjects or from WP athletes in Hep $\mathrm{G} 2$ cells after $24 \mathrm{~h}$ and $48 \mathrm{~h}$ of incubation (Fig. 2). After $48 \mathrm{~h}$ of incubation, the phosphorylation of AMPK $\alpha$ and ACC statistically increased in the cells treated with WP players' sera, compared to that treated with the sera from the other used sera.

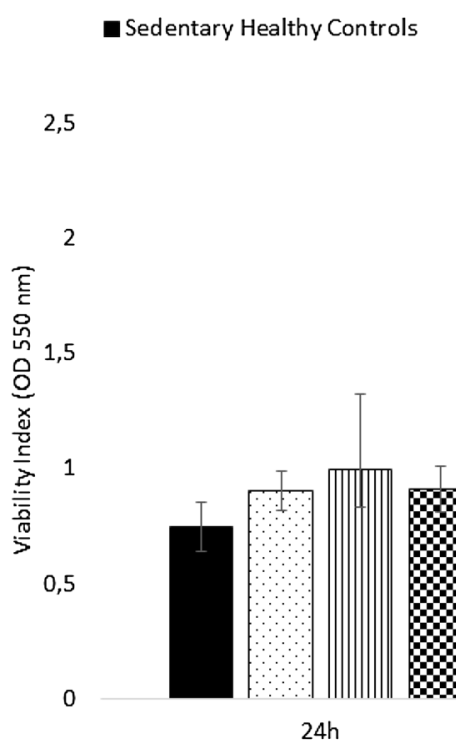

Fig. 1 Treatments with sera from the different trained subjects do not affect cell viability of HepG2. Hep G2 cells were treated with sera from Water Polo players, Basket players, obeses and healthy controls

\section{Cytokine levels in water polo players and sedentary healthy controls sera}

Considering that the treatment of Hep G2 cells with Water Polo players' sera induces the activation of AMPK and ACC, and as it is known that exercise modulates cytokine production, we analysed the levels of IL-2, IL-4, IL-6, IL-8, IL-10, TNF- $\alpha$, GM-CSF and IFN- $\gamma$ cytokines in sera from Water Polo players and compared them to sedentary healthy controls. Serum levels of IL-4, IL-6 and IL-10 were statistically increased in WP players compared to controls (Fig. 3, panels A, B and C). Also, we found that IL-2, and IL-8 and GMCSF levels are increased in athlete's sera than in control subjects even if the difference is not statistically relevant (data not shown). Finally, TNF- $\alpha$ and INF- $\gamma$ were not differentially expressed between athletes and controls (data not shown).

\section{Discussion}

Healthy habits such as correct nutrition and physical activity are the first-line approach for prevention and treatment of liver disorders. Indeed, it is well known that physical activity could work as a potent anti-inflammatory factor, counteracting liver inflammation typical of metabolic disorders and ameliorating lipid metabolism. On the contrary, bad habits such as overeating and a sedentary lifestyle lead to metabolic disorders which are negatively affect liver health [13]. Starting from this evidence, in the present study we collected sera from 22 WP players, 3 amatorial basket players, 3 obese subjects and 20 control subjects and studied the $\square$ Obese subjects $\square$ Basket players Polo players

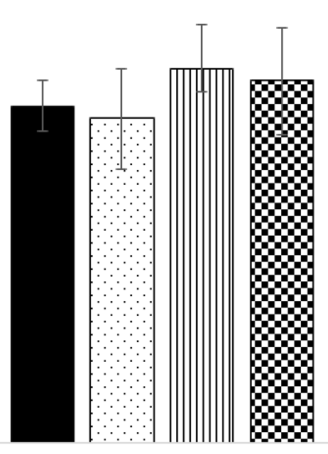

$48 \mathrm{~h}$

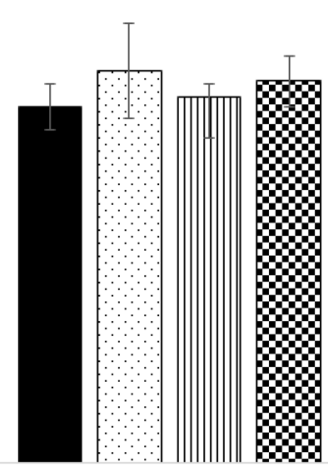

$72 \mathrm{~h}$ and checked for the viability. No statistically relevant variations were found in cell viability after $24 \mathrm{~h}, 48 \mathrm{~h}$ and $72 \mathrm{~h}$ of incubation 


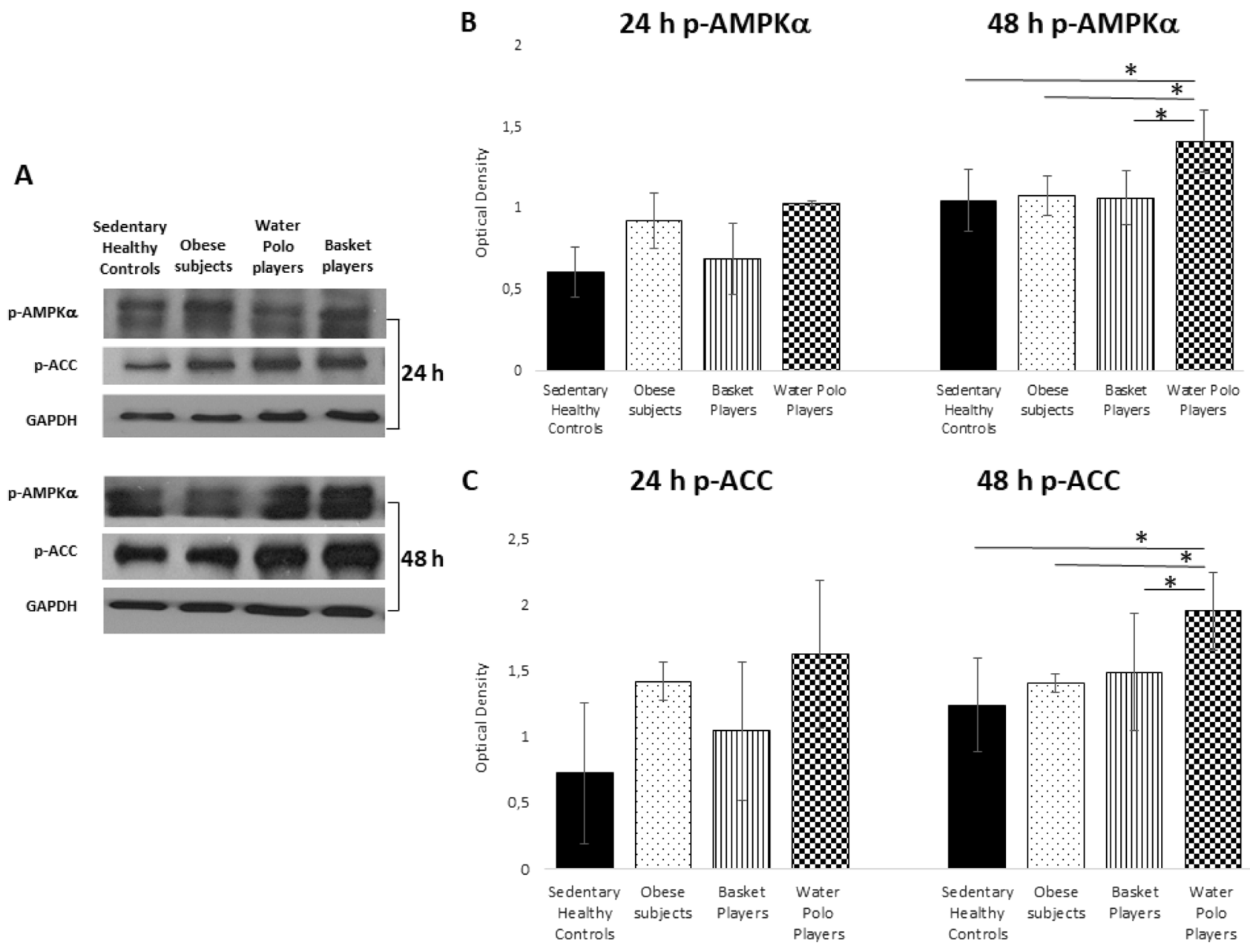

Fig. 2 Treatment of Hep G2 cells with sera from professional WP athletes induces the phosphorylation of AMPK $\alpha$ and ACC. Treatment of Hep G2 cells with WP players' sera increases the phosphorylation of AMPK $\alpha$ and ACC compared to cells treated with basket players, obese subjects and sedentary healthy controls sera after $48 \mathrm{~h}$ of

effects of treatment with these sera of HepG2, a hepatoma cell line [31]. We first investigated the effects in terms of cell viability founding that all sera do not modulate cell growth. Accordingly, Conti et al. [32] demonstrated that the treatment with sera from different type of athletes does not alter cell viability of endothelial cells, but, interestingly, induced an increase of cell survival; we did not observe any increase in cell survival but this discrepancy may be explained by the difference in the cell models utilized and/or by the physical activity of the athletes recruited in the two analysed studies.

Then, we investigated the activation status of two key molecules involved in both metabolism and energy balance, AMPK $\alpha$ and ACC. Activation of AMPK $\alpha$ in liver leads to the stimulation of fatty acid oxidation and inhibition of lipogenesis through inhibition of ACC [33]. Regular physical exercise has been described as the most powerful nonpharmacological therapeutic approach in the prevention and incubation. a representative images of three replicate experiments. b, c Quantitative data with graphs showing the densitometric intensity of pAMPK $\alpha / \mathrm{GAPDH}, \mathrm{pACC} / \mathrm{GAPDH}$ bands ratio. Values represent means \pm SE of experiments performed two times in triplicate. The intensities of signals were expressed as arbitrary units. $* P<0.05$

treatment of disorders associated with metabolic dysfunctions through the regulation of metabolic and inflammatory processes [34]. The molecular pathways beyond these effects are mainly mediated by the activation of $\operatorname{AMPK} \alpha[35,36]$. Our results showed that WP athlete's sera increase the phosphorylation of AMPK $\alpha$ and ACC respect to sera of obese and of control subjects. It has been shown that, in skeletal muscle, AMPK $\alpha$ modulates the phosphorylation with the resulting inhibition of $\mathrm{ACC}$, the limiting enzyme in the malonyl CoA synthesis $[37,38]$. AMPK $\alpha$ plays an important role in regulating lipid metabolism in multiple tissues after exercise. Chen et al. [39] reported that in lean mice performing exercise, the phosphorylation levels of AMPK $\alpha$ strongly increase compared to obese and controls mice. In accordance with our study, Gibala et al. [40] reported that intense interval exercise induces metabolic remodelling through AMPK $\alpha$ activation. 



IL-10



Fig. 3 The expression of IL-4, IlL6, IL-10 cytokines is statistically increased in WP player's sera compared to sedentary healthy controls: Serum levels of IL-4, IL-6 and IL-10 were statistically increased in WP players compared to controls $(\mathbf{a}, \mathbf{b}, \mathbf{c})$

Considering that in our study WP player's sera induce a relevant effect in terms of AMPK/ACC activation, we next investigated cytokine levels in the sera from the athletes assuming that an increased and/or decrease of cytokines might have been responsible for the effects of sera on Hep G2. Indeed, cytokines have important roles in many physiological and pathological conditions [13, 14]. In particular, professional sports can induce the release of pro- and antiinflammatory cytokines among of these, the IL-6 plays a dominant role [41] but several authors found increased levels also of TNF- $\alpha$, IL-1, IL-4,, IL-10, and IL-8 [42-45]. In the sera from the athletes we found a statistical increase of IL-4, IL-6, and IL-10 levels compared to controls. In accordance with our data, Nemet et al. found increased levels of IL-6 in a group of WP players [46]. In addition, several studies suggest that IL- 6 is induced by exercise and involved in mediating exercise-related metabolic changes. Although to our knowledge there are no available data about IL-4 and IL-10 in WP, a beneficial role for the anti-inflammatory cytokines IL-4 and IL-10 has been suggested by many studies in different cohorts of athletes $[43,45]$. Our data are indicative that an anti-inflammatory environment is induced by exercise in WP resulting in cytokine production that in turn might participate in stimulating AMPK $\alpha$ pathway in cells.

\section{Conclusions}

We demonstrated that professional sport activity such as WP can induce an in vivo anti-inflammatory milieu and that possibly determines an increase in the phosphorylation status of AMPK $\alpha$ and consequently of ACC in Hep $\mathrm{G} 2$ cells. This activation, together with the modulation of cytokine production and release, may be, at least in part, at the basis of the beneficial preventing effects exerted by exercise towards disorders associated with the metabolism.

Acknowledgments The authors thank the project "POR FESR 2014/2020 ASSE I -iCURE”, Regione Campania.

Author contributions RP and EN performed the experiments, MLM conducted the statistical analysis. MM and AE recruited the participants. EN and AD wrote the manuscript.

Funding Open access funding provided by Università degli Studi della Campania Luigi Vanvitelli within the CRUI-CARE Agreement.. No funds were given for this research.

\section{Compliance with ethical standards}

Conflict of interest The authors declare no potential conflict of interest. 
Ethical approval The study was conducted according to the guidelines of the Declaration of Helsinki and approved by the Ethics Committee of University of Campania “L. Vanvitelli” (Prot. n. 587/18).

Informed consent All participants signed informed consent.

Open Access This article is licensed under a Creative Commons Attribution 4.0 International License, which permits use, sharing, adaptation, distribution and reproduction in any medium or format, as long as you give appropriate credit to the original author(s) and the source, provide a link to the Creative Commons licence, and indicate if changes were made. The images or other third party material in this article are included in the article's Creative Commons licence, unless indicated otherwise in a credit line to the material. If material is not included in the article's Creative Commons licence and your intended use is not permitted by statutory regulation or exceeds the permitted use, you will need to obtain permission directly from the copyright holder. To view a copy of this licence, visit http://creativecommons.org/licenses/by/4.0/.

\section{References}

1. Elce A et al (2018) Supervised physical exercise improves clinical, anthropometric and biochemical parameters in adult cystic fibrosis patients: a 2-year evaluation. Clin Respir J. https://doi. org/10.1111/crj.12796

2. Nigro E et al (2014) New insight into adiponectin role in obesity and obesity-related diseases. Biomed Res Int. https://doi.org/10. 1155/2014/658913

3. Bray GA, Kim KK, Wilding PH (2017) Obesity: a chronic relapsing progressive disease process. a position statement of the world obesity federation. Obes Rev J Internat Assoc Study Obesity 18:715-723. https://doi.org/10.1111/obr.12551

4. Fujii H, Kawada N, Jsg-Nafld JSGON (2020) The role of insulin resistance and diabetes in nonalcoholic fatty liver disease. Int $\mathrm{J}$ Mol Sci 21:11. https://doi.org/10.3390/ijms21113863

5. Kadowaki $\mathrm{S}$ et al (2019) Fatty liver has stronger association with insulin resistance than visceral fat accumulation in nonobese Japanese Men. J Endocr Soc 3:1409-1416. https://doi.org/10.1210/js. 2019-00052

6. Matsubayashi $\mathrm{Y}$ et al (2018) Role of fatty liver in the association between obesity and reduced hepatic insulin clearance. Diabetes Metab 44:135-142. https://doi.org/10.1016/j.diabet.2017.12.003

7. Cansby E, Nerstedt A, Amrutkar M, Durán EN, Smith U, Mahlapuu M (2014) Partial hepatic resistance to IL-6-induced inflammation develops in type 2 diabetic mice, while the antiinflammatory effect of AMPK is maintained. Mol Cell Endocrinol 393(1-2):143-151. https://doi.org/10.1016/j.mce.2014.06.014

8. Osawa $\mathrm{Y}$ et al (2018) Tumor necrosis factor- $\alpha$-mediated hepatocyte apoptosis stimulates fibrosis in the steatotic liver in mice. Hepatol Commun 2(4):407-420. https://doi.org/10.1002/hep4. 1158

9. Tayer-Shifman OE, Bar-On Y, Pereg D, Hershko AY (2018) Physical training in a medical fitness room for patients with chronic diseases: functional and metabolic outcomes. Isr Med Assoc J 20(1):20-24

10. Cartee GD, Hepple RT, Bamman MM, Zierath JR (2016) Exercise promotes healthy aging of skeletal muscle. Cell Metab 23(6):1034-1047. https://doi.org/10.1016/j.cmet.2016.05.007

11. Smith HK (1998) Applied physiology of water polo. Sports Med 26:317-334

12. Kujala UM (2018) Is physical activity a cause of longevity? It is not as straightforward as some would believe. A critical analysis.
Br J Sports Med 52(14):914-918. https://doi.org/10.1136/bjspo rts-2017-098639

13. Nigro E et al (2020) Molecular mechanisms involved in the positive effects of physical activity on coping with COVID-19. Eur J Appl Physiol 120(12):2569-2582

14. Grazioli E et al (2020) Case report: concurrent resistance and aerobic training regulate adiponectin expression and disease severity in multiple sclerosis: a case study. Front Neurosci 14:567302

15. Woods JA, Wilund KR, Martin SA, Kistler BM (2012) Exercise, inflammation and aging. Aging Dis 3(1):130-140

16. Nicklas BJ et al (2008) Exercise training and plasma C-reactive protein and interleukin-6 in elderly people. J Am Geriatr Soc 56(11):2045-2052. https://doi.org/10.1111/j.1532-5415.2008. 01994.x

17. Lancaster GI, Febbraio MA (2014) The immunomodulating role of exercise in metabolic disease. Trends Immunol 35(6):262-269. https://doi.org/10.1016/j.it.2014.02.008

18. Pedersen BK (2017) Anti-inflammatory effects of exercise: role in diabetes and cardiovascular disease. Eur J Clin Invest 47(8):600 611. https://doi.org/10.1111/eci.12781

19. Gonzalez-Gil AM, Elizondo-Montemayor L (2020) The role of exercise in the interplay between myokines, hepatokines, osteokines, adipokines, and modulation of inflammation for energy substrate redistribution and fat mass loss: a review. Nutrients 12(6):9. https://doi.org/10.3390/nu12061899

20. Pedersen BK, Febbraio MA (2008) Muscle as an endocrine organ: focus on muscle-derived interleukin-6. Physiol Rev 88(4):1379 1406. https://doi.org/10.1152/physrev.90100.2007

21. Fernandes P, de Mendonça OL, Brüggemann TR, Sato MN, Olivo CR, Arantes-Costa FM (2019) Physical exercise induces immunoregulation of TREG, M2, and pDCs in a lung allergic inflammation model. Front Immunol 10:854. https://doi.org/10.3389/ fimmu.2019.00854

22. Abbasi A et al (2014) Exhaustive exercise modifies different gene expression profiles and pathways in LPS-stimulated and un-stimulated whole blood cultures. Brain Behav Immun 39:130-141. https://doi.org/10.1016/j.bbi.2013.10.023

23. Tanaka T, Narazaki M, Kishimoto T (2014) IL-6 in inflammation, immunity, and disease. Cold Spring Harb Perspect Biol 6(10):a016295. https://doi.org/10.1101/cshperspect.a016295

24. Schmidt-Arras D, Rose-John S (2016) IL-6 pathway in the liver: From physiopathology to therapy. J Hepatol 64(6):1403-1415. https://doi.org/10.1016/j.jhep.2016.02.004

25. Zhang Y, Chen J, Zeng Y, Huang D, Xu Q (2019) Involvement of AMPK activation in the inhibition of hepatic gluconeogenesis by Ficus carica leaf extract in diabetic mice and HepG2 cells. Biomed Pharmacother 109:188-194. https://doi.org/10.1016/j. biopha.2018.10.077

26. Smith BK, Marcinko K, Desjardins EM, Lally JS, Ford RJ, Steinberg GR (2016) Treatment of nonalcoholic fatty liver disease: role of AMPK. Am J Physiol Endocrino Metab 311(4):E730-E740. https://doi.org/10.1152/ajpendo.00225.2016

27. Nigro E et al (2016) Gene molecular analysis and Adiponectin expression in professional Water Polo players. Cytokine 81:88-93. https://doi.org/10.1016/j.cyto.2016.03.002

28. Corbi G et al (2019) Adiponectin expression and genotypes in italian people with severe obesity undergone a hypocaloric diet and physical exercise program. Nutrients. https://doi.org/10.3390/ nu11092195

29. Sapio L et al (2020) AdipoRon affects cell cycle progression and inhibits proliferation in human osteosarcoma cells. J Oncol. https://doi.org/10.1155/2020/7262479

30. Polito R et al (2020) Adiponectin is inversely associated with tumour grade in colorectal cancer patients. Anticancer Res 40(7):3751-3757. https://doi.org/10.21873/anticanres.14364 
31. Pramfalk C, Larsson L, Härdfeldt J, Eriksson M (1861) Parini P (2016) Culturing of HepG2 cells with human serum improve their functionality and suitability in studies of lipid metabolism. Biochim Biophys Acta 1:51-59. https://doi.org/10.1016/j.bbalip. 2015.10.008

32. Conti V et al (2012) Oxidative stress effects on endothelial cells treated with different athletes' sera. Med Sci Sports Exerc 44(1):39-49. https://doi.org/10.1249/MSS.0b013e318227f69c

33. Viollet $\mathrm{B}$ et al (2006) Activation of AMP-activated protein kinase in the liver: a new strategy for the management of metabolic hepatic disorders. J Physiol 574(1):41-53. https://doi.org/10.1113/ jphysiol.2006.108506

34. Lakka TA, Laaksonen DE (2007) Physical activity in prevention and treatment of the metabolic syndrome. Appl Physiol Nutr Metab Physiol Appl Nutr Metab 32(1):76-88. https://doi.org/10. 1139/h06-113

35. Ruderman NB et al (2003) AMPK as a metabolic switch in rat muscle, liver and adipose tissue after exercise. Acta Physiol Scand 178(4):435-442. https://doi.org/10.1046/j.1365-201X.2003. 01164.X

36. Richter EA, Ruderman NB (2009) AMPK and the biochemistry of exercise: implications for human health and disease. Biochem J 418(2):261-275. https://doi.org/10.1042/BJ20082055

37. Schon HT, Weiskirchen R (2016) Exercise-induced release of pharmacologically active substances and their relevance for therapy of hepatic injury. Front Pharmacol 7:283. https://doi.org/10. 3389/fphar.2016.00283

38. Schwalm C et al (2015) Activation of autophagy in human skeletal muscle is dependent on exercise intensity and AMPK activation. FASEB J Off Publ Fed Am Soc Exp Biol 29(8):3515-3526. https://doi.org/10.1096/fj.14-267187

39. Chen YC, Lee SD, Kuo CH, Ho LT (2010) The effects of altitude training on the AMPK-related glucose transport pathway in the red skeletal muscle of both lean and obese Zucker rats. High Alt Med Biol 12(4):371-378. https://doi.org/10.1089/ham.2010.1088

40. Gibala MJ, McGee SL, Garnham AP, Howlett KF, Snow RJ, Hargreaves M (2009) Brief intense interval exercise activates AMPK and p38 MAPK signaling and increases the expression of PGC1alpha in human skeletal muscle. J Appl Physiol 106(3):929-934. https://doi.org/10.1152/japplphysiol.90880.2008

41. Yi X et al (2013) Effects of acute exercise and chronic exercise on the liver leptin-AMPK-ACC signaling pathway in rats with type 2 diabetes. J Diabetes Res 2013:946432. https://doi.org/10.1155/ 2013/946432

42. Streetz KL, Luedde T, Manns MP, Trautwein C (2000) Interleukin 6 and liver regeneration. Gut 47(2):309-312. https://doi.org/10. 1136/gut.47.2.309

43. Minuzzi LG et al (2019) Lifelong exercise practice and immunosenescence: master athletes cytokine response to acute exercise. Cytokine 115:1-7. https://doi.org/10.1016/j.cyto.2018.12.006

44. Pedersen BK et al (2000) Cytokines in aging and exercise. Int $\mathbf{J}$ Sports Med 21(1):S4-9. https://doi.org/10.1055/s-2000-1444

45. Gleeson M (2007) Immune function in sport and exercise. J Appl Physiol 103(2):693-699. https://doi.org/10.1152/japplphysiol. 00008.2007

46. Nemet D, Rose-Gottron CM, Mills PJ, Cooper DM (2003) Effect of water polo practice on cytokines, growth mediators, and leukocytes in girls. Med Sci Sports Exerc 35(2):356-363. https://doi. org/10.1249/01.MSS.0000048722.84182.E3

Publisher's Note Springer Nature remains neutral with regard to jurisdictional claims in published maps and institutional affiliations. 